\title{
Shoulder Adhesive Capsulitis in Type 1 Diabetes Mellitus: A Cross-Sectional Study on 943 Cases in Sardinian People
}

\author{
Carlo Doria ${ }^{1}$ Giulia R. Mosele ${ }^{1}$ Francesca Badessi ${ }^{2}$ Leonardo Puddu ${ }^{1}$ Gianfilippo Caggiari
}

${ }^{1}$ Department of Orthopaedic, Medical School of Sassari, Sassari, Italy

2 Division of Endocrinology and Metabolism, Medical School of

Sassari, Sassari, Italy

Address for correspondence Gianfilippo Caggiari, MD, Department of Orthopaedic, University of Sassari, Viale San Pietro 47, Sassari 07100, Italy (e-mail: gianfilippocaggiari@gmail.com).

Joints 2017;5:143-146.

\begin{abstract}
Purpose To evaluate the prevalence of adhesive capsulitis (AC) of the shoulder in patients with type 1 diabetes mellitus (T1DM) in Sardinia.

Methods In this cross-sectional study, we evaluated 943 patients with T1DM attending the division of Endocrinology and Metabolism at the University Hospital in Sassari, Italy. The criteria for diagnosing AC were: pain for at least 1 month, inability to lie on the affected shoulder, and restricted active and passive shoulder joint movements in at least three planes. Age, gender, duration of DM, blood pressure, and presence of neuropathy and retinopathy were noted. Metabolic control of DM was evaluated with glycosylated hemoglobin A1c (GHbA1c) blood concentrations.

Results AC was diagnosed in 331 patients (prevalence: 35.1\%). Age, duration of DM, high blood pressure levels, and the presence of neuropathy and retinopathy were significantly associated with AC. No significant association was observed between

Keywords

- adhesive capsulitis

- diabetes mellitus

- prevalence

- Sardinia

- shoulder gender and AC. There was no significant difference in mean levels of GHbA1c in T1DM patients with or without AC.

Conclusion This study shows that AC of the shoulder is a common disorder in patients with T1DM in Sardinia. It is significantly associated with age, duration of DM, and related complications.

Level of Evidence Level IV, observational cross-sectional study.
\end{abstract}

\section{Introduction}

Adhesive capsulitis (AC) is a common, painful condition of the shoulder that is associated with loss of range of motion (ROM) in the glenohumeral (GH) joint. It results from contraction of the $\mathrm{GH}$ joint capsule and adherence to the humeral head. ${ }^{1}$

AC has traditionally been characterized as primary or secondary resulting from an underlying condition, such as diabetes mellitus (DM), rotator cuff tendinopathy or tear, subacromial bursitis, biceps tendinopathy, previous shoulder surgery or trauma, and systemic inflammatory diseases. ${ }^{2,3}$ The incidence of $\mathrm{AC}$ is approximately $3 \%$ in the general population; it is rare in children, and peaks between
40 and 70 years of age. ${ }^{4}$ It is very common in persons with diabetes. $^{5}$

Type 1 DM (T1DM) results from an autoimmune destruction of insulin-producing $\beta$ cells. ${ }^{6}$ Although T1DM accounts for 5 to $10 \%$ of the total burden of DM, it is the predominant endocrine disease in childhood and adolescence. There are approximately 500,000 children aged under 15 years with T1DM in the world. ${ }^{7}$ Worldwide, the incidence of T1DM has increased, on average, 3\% per year between 1960 and 1996 in children under 15 years of age. ${ }^{8}$ This trend is especially troublesome in the youngest children; for every 100,000 children under the age of 5 years, $4 \%$ were diagnosed every year, on average, worldwide. ${ }^{9}$ published online August 24, 2017
DOI https://doi.org/ 10.1055/s-0037-1605555. ISSN 2282-4324.
Copyright @ 2017 Georg Thieme Verlag KG Stuttgart · New York
License terms

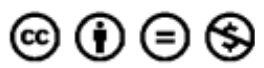


From an epidemiological point of view, Sardinia, the second largest Italian Mediterranean island, has the second highest incidence of T1DM in the world after Finland. ${ }^{10}$ Both areas have shown significant annual increases in incidence rates over the second half of the 20th century and the beginning of the new millennium. Both populations are genetically stable implying a significant role for environmental factors. The relation between $\mathrm{DM}$ and $\mathrm{AC}$ has been shown in few previous studies. Bridgman reviewed the medical records of 800 diabetic subjects and found evidence of periarthritis in $10.8 \%$ compared with $2.3 \%$ in a control group of 600 nondiabetic subjects. ${ }^{11}$ Other authors ${ }^{12}$ found shoulder capsulitis in $20.4 \%$ of patients with insulin-dependent and in $18.3 \%$ of patients with noninsulin-dependent diabetes and in $5.3 \%$ of normal subjects. In a study of 824 type II diabetic and 320 control subjects, shoulder capsulitis was observed in 31.8 and $10.3 \%$ of subjects, respectively. ${ }^{13}$ The natural history of the disease is characterized by three distinct phases: painful, adhesive, and resolution. ${ }^{14}$

Adhesive capsulitis appears at a younger age in patients with diabetes and is usually less painful, although it responds less well to treatment and lasts longer. ${ }^{15}$ The estimated prevalence is 11 to $30 \%$ in patients with diabetes and 2 to $10 \%$ in nondiabetics. ${ }^{16}$

AC is associated with the duration of diabetes and age. ${ }^{17}$ Most cases of $\mathrm{AC}$ will resolve over time, but in the interim, management consists of adequate analgesia and intra-articular corticosteroid (CS) injections in the painful early stages, if required. Capsular distension induced by intraarticular hyaluronic acid (HA) injections or manipulation under anesthesia is occasionally considered. ${ }^{18}$ An appropriately graded, regular physiotherapy program should be maintained after the painful phase and throughout the course of the condition. For patients with loss of motion refractory to closed manipulation, arthroscopic capsular release has been shown to improve motion with minimal operative morbidity. ${ }^{19}$

Recent study demonstrated a 350-fold difference in the incidence of T1D among 100 populations worldwide and reported age-adjusted incidences ranging from a low of $0.1 / 100,000$ per year in China and Venezuela to a high of $36.5 / 100,000$ in Finland and 36.8/100,000 per year in Sardinia. ${ }^{20}$

The purpose of this study was to investigate the prevalence of shoulder AC in Sardinian patients with T1DM.

\section{Methods}

In this cross-sectional study, we evaluated 943 patients (437 women, 506 men) with DM attending the division of Endocrinology and Metabolism at the University Hospital in Sassari. This study was conducted in accordance with Good Clinical Practice guidelines and principles of the Declaration of Helsinki, and all patients gave their consent for using the data. All patients had T1DM with criteria of the World Health Organization. Their ages ranged from 29 to 71 (mean \pm SD: $51.33 \pm 8.45$ years) years. The following variables were recorded: age, gender, duration of the disease, blood pressure, and the presence of peripheral neuropathy and retino- pathy. Metabolic control of DM was evaluated with glycosylated hemoglobin $A_{1 c}\left(G_{H b} A_{1 c}\right)$ blood concentration. The specific symptoms of somatic peripheral symmetrical neuropathy were: pain, paraesthesia, tickling, and muscle weakness. The patients were considered to have neuropathy if they had typical symptoms and impaired vibratory sensation or if ankle jerks were absent. Nerve conduction of these patients was measured with electroneuromyography. Retinal examination was performed by experienced ophthalmologists, with fundoscopy after dilatation of the pupils with a mydriatic agent. Retinopathy was classified as normal, background, or proliferative. The criteria for AC, previously described by Pal et $\mathrm{al}^{20}{ }^{20}$ were: shoulder pain for at least 1 month, an inability to lie on the affected shoulder, and restricted active and passive shoulder joint movements in at least three planes.

Statistical evaluation was performed with Pearson's chisquared test, Spearman's correlation test, Mann-Whitney U-test, independent sample $t$-test, and Wilcoxon signed-rank test. Statistical significance was defined as $p<0.05$.

\section{Results}

AC of the shoulder was diagnosed in 331 patients (177 in men and 154 in women, - Table 1); right and left sides were involved in 169 and 75 patients, respectively; in 87 patients, the disease was bilateral. The mean age was $44.4 \pm 8.1$ years in patients with $\mathrm{AC}$ and $33.9 \pm 8.6$ years in patients without AC $(p<0.01)$. AC was not associated with gender $(p=0.24)$. Duration of DM in patients with and without AC was $29.3 \pm 7.1$ and $16.1 \pm 8.4$ years, respectively $(p<0.01)$. Twenty percent of T1DM patients with hypertension and $6 \%$ of patients without hypertension had $\mathrm{AC}(p<0.01)$. Three percent of T1DM patients without neuropathy and $20 \%$ with neuropathy had AC $(p<0.01)$. There was significant association with proliferative retinopathy $(p=0.01)$. There was no significant difference in mean levels of $\mathrm{GHbA}_{1 \mathrm{c}}$ in patients with or without $A C$. AC was more frequent in patients with poor control of $\mathrm{DM}\left(\mathrm{GHbA}_{1 \mathrm{c}}>8 \%\right)$ than in patients with better controlled disease, albeit this association was not significant.

\section{Discussion}

This study shows that AC is a common disorder in patients with T1DM in Sardinia. It is important to note that the patients examined in our study were enrolled at the same hospital and came from the northwest of Sardinia, where the incidence of T1DM is significantly low compared with other areas of the island. Therefore, our data may underestimate the actual incidence of DM and its complications throughout our region. The geographical distribution of T1DM within the four provinces of the Sardinia was mapped, showing that the highest incidence ("hot spot") was in the middle-western part of the island (Oristano province, $45 / 100,000$ ) followed by Cagliari $(38 / 100,000)$, and Nuoro $(35 / 100,000)$. The province with the lowest incidence ("cold spot") was in the north-western part (Sassari province, 30/100,000) of the 
Table 1 Clinical characteristics of T1DM patients with and without AC

\begin{tabular}{|c|c|c|c|}
\hline $\begin{array}{l}\text { Study group } \\
n=943\end{array}$ & $\begin{array}{l}\mathrm{AC} \\
n=331(35.1 \%)\end{array}$ & $\begin{array}{l}\text { Controls (no AC) } \\
n=612(64.9 \%)\end{array}$ & $p$-Value \\
\hline Age, y (mean \pm SD) & $44.4 \pm 8.1$ & $33.9 \pm 8.6$ & $<0.01$ \\
\hline Gender (Men/Women) & $187 / 144$ & $325 / 287$ & 0.24 \\
\hline $\begin{array}{l}\text { Duration of T1DM, y } \\
(\text { mean } \pm \text { SD) }\end{array}$ & $29.3 \pm 7.1$ & $16.1 \pm 8.4$ & $<0.01$ \\
\hline Hypertension, n (\%) & $87(26.3)$ & $105(17.1)$ & $<0.01$ \\
\hline Neuropathy $n(\%)$ & $93(28.1)$ & $113(18.4)$ & $<0.01$ \\
\hline \multicolumn{4}{|l|}{ Retinopathy } \\
\hline Normal, $n(\%)$ & $20 / 80(25.0)$ & $24 / 67(35.8)$ & \multirow[t]{3}{*}{0.01} \\
\hline Background n (\%) & $26 / 80(32.5)$ & $27 / 67(40.3)$ & \\
\hline Proliferative $n(\%)$ & $34 / 80(42.5)$ & $16 / 67(23.9)$ & \\
\hline $\mathrm{GHbA}_{1 c}($ mean $\pm \mathrm{SD})$ & $9.1 \pm 2.0$ & $8.5 \pm 1.7$ & 0.55 \\
\hline
\end{tabular}

Abbreviations: AC, adhesive capsulitis; GHbA, glycosylated hemoglobin A1c; SD, standard deviation; T1DM, type 1 diabetes mellitus.

island. ${ }^{21}$ Our data report that the presence of AC was highly dependent on the age and the duration of DM, with the prevalence increasing after the age of 40 and 50 years. Our study also showed an association between $\mathrm{AC}$ and proliferative retinopathy in T1DM patients, but the correlation was fully explained by age and the duration of DM. Although no significant association was found between $\mathrm{AC}$ and the control of DM, the best therapy is prophylaxis with good control of glycemic values.

The presence of idiopathic AC of the shoulder should be established through a correct differential diagnosis versus secondary shoulder stiffness. The condition is diagnosed on clinical symptoms and signs, as there are no reliable diagnostic tests. Definitive diagnosis of $\mathrm{AC}$ is achieved only through direct surgical observation. The GH joint capsule is comprised of soft tissue and is therefore not visible on plain radiography. Magnetic resonance imaging (MRI) is not diagnostic for AC but can be helpful in identifying other conditions, such as rotator cuff tendinopathy and subacromial bursitis.

Early mobilization may prevent shoulder motion limitation. All patients with shoulder AC may be followed closely for shoulder motion limitation so that upper extremity function disability may be prevented. However, diabetic patients show a certain resistance to conservative treatment of AC. Morphological examination of pathological capsular tissue samples taken intraoperatively has shown the presence of newly vascularized synovial tissue, while immunohistochemical examination has revealed the presence of vascular endothelial growth factor, which has the capacity to induce intense synovial neovascularization. ${ }^{22}$ Furthermore, a high presence of intercellular adhesion molecule-1 has been found in shoulder capsule tissue of patients with diabetes, correlating with inflammation and fibrosis. ${ }^{23}$

In conclusion, this study confirmed that $\mathrm{AC}$ is a common disorder in Sardinian people with T1DM. It is associated with age and the duration of DM, which explains most of its correlations with diabetic complications.

\section{Authors' Contributions}

C.R. wrote the manuscript. G.R.M. wrote the manuscript and researched the data. G.C., L.P., and F.B. contributed to discussion and researched data. No payment or services were received from the third party for any grant, consulting fee or honorarium, support for travel to meetings for the study or other purposes, fees for participation in review activities, such as data monitoring boards, statistical analysis, endpoint committees, and payment for writing or reviewing the manuscript, provision of writing assistance, medicines, equipment, or administrative support. The authors do not hold any relevant financial relationships or activities outside the submitted work. No payment was provided for lectures, including service on speakers' bureaus and manuscript preparation. No other relationships/conditions/circumstances that present a potential conflict of interest exist.

\section{Conflict of Interest}

None.

\section{References}

1 Manske RC, Prohaska D. Diagnosis and management of adhesive capsulitis. Curr Rev Musculoskelet Med 2008;1(3-4):180-189

2 van der Windt DA, Koes BW, de Jong BA, Bouter LM. Shoulder disorders in general practice: incidence, patient characteristics, and management. Ann Rheum Dis 1995;54(12):959-964

3 Binder AI, Bulgen DY, Hazleman BL, Tudor J, Wraight P. Frozen shoulder: an arthrographic and radionuclear scan assessment. Ann Rheum Dis 1984;43(03):365-369

4 Modesto C, Crespo E, Villas C, Aquerreta D. Adhesive capsulitis. Is it possible in childhood? Scand J Rheumatol 1995;24(04): 255-256 
5 Tighe CB, Oakley WS Jr. The prevalence of a diabetic condition and adhesive capsulitis of the shoulder. South Med J 2008;101(06): 591-595

6 Borg WP, Sherwin RS. Classification of diabetes mellitus. Adv Intern Med 2000;45:279-295

7 Patterson C, Guariguata L, Dahlquist G, Soltész G, Ogle G, Silink M. Diabetes in the young - a global view and worldwide estimates of numbers of children with type 1 diabetes. Diabetes Res Clin Pract 2014;103(02):161-175

8 Onkamo P, Väänänen $S$, Karvonen $M$, Tuomilehto J. Worldwide increase in incidence of Type I diabetes-the analysis of the data on published incidence trends. Diabetologia 1999;42(12):1395-1403

9 DIAMOND Project Group. Incidence and trends of childhood Type 1 diabetes worldwide 1990-1999. Diabet Med 2006;23(08): 857-866

10 Green A, Patterson CC; EURODIAB TIGER Study Group. Europe and Diabetes. Trends in the incidence of childhood-onset diabetes in Europe 1989-1998. Diabetologia 2001;44(Suppl 3):B3-B8

11 Bridgman JF. Periarthritis of the shoulder and diabetes mellitus. Ann Rheum Dis 1972;31(01):69-71

12 Pal B, Anderson J, Dick WC, Griffiths ID. Limitation of joint mobility and shoulder capsulitis in insulin- and non-insulin-dependent diabetes mellitus. Br J Rheumatol 1986;25(02):147-151

13 Mavrikakis ME, Sfikakis PP, Kontoyannis SA, Antoniades LG, Kontoyannis DA, Moulopoulou DS. Clinical and laboratory parameters in adult diabetics with and without calcific shoulder periarthritis. Calcif Tissue Int 1991;49(04):288-291

14 Reeves B. The natural history of the frozen shoulder syndrome. Scand J Rheumatol 1975;4(04):193-196
15 Griggs SM, Ahn A, Green A. Idiopathic adhesive capsulitis. A prospective functional outcome study of nonoperative treatment. J Bone Joint Surg Am 2000;82-A(10):1398-1407

16 Lequesne M, Dang N, Bensasson M, Mery C. Increased association of diabetes mellitus with capsulitis of the shoulder and shoulderhand syndrome. Scand J Rheumatol 1977;6(01):53-56

17 Balci N, Balci MK, Tüzüner S. Shoulder adhesive capsulitis and shoulder range of motion in type II diabetes mellitus: association with diabetic complications. J Diabetes Complications 1999;13(03): 135-140

18 Meloni F, Milia F, Cavazzuti M, et al. Clinical evaluation of sodium hyaluronate in the treatment of patients with sopraspinatus tendinosis under echographic guide: experimental study of periarticular injections. Eur J Radiol 2008;68(01):170-173

19 Warner JJ, Allen A, Marks PH, Wong P. Arthroscopic release for chronic, refractory adhesive capsulitis of the shoulder.J Bone Joint Surg Am 1996;78(12):1808-1816

20 Maahs DM, West NA, Lawrence JM, Mayer-Davis EJ. Chapter 1: Epidemiology of Type 1 Diabetes. Endocrinol Metab Clin North Am 2010;39(03):481-497

21 Songini M, Lombardo C. The Sardinian way to type 1 diabetes. J Diabetes Sci Technol 2010;4(05):1248-1255

22 Ryu JD, Kirpalani PA, Kim JM, Nam KH, Han CW, Han SH. Expression of vascular endothelial growth factor and angiogenesis in the diabetic frozen shoulder. J Shoulder Elbow Surg 2006;15(06): 679-685

23 Kim YS, Kim JM, Lee YG, Hong OK, Kwon HS, Ji JH. Intercellular adhesion molecule-1 (ICAM-1, CD54) is increased in adhesive capsulitis. J Bone Joint Surg Am 2013;95(04):e181-e188 